\title{
COMPARISON OF STRESSES TRANSMITTED TO ONE- PIECE AND TWO-PIECE NARROW-DIAMETER IMPLANTS IN MANDIBULAR OVER DENTURES (A FINITE ELEMENT STRESS ANALYSIS)
}

\author{
Sarah M. Moustafa ${ }^{1} B D S$, Mohamed S. Elattar ${ }^{2} P h D$, \\ Tamer M. Ahmed ${ }^{3} P h D$.
}

\begin{abstract}
INTRODUCTION: The goal of modern dentistry is to restore the patient to normal contour, function and esthetics. And what makes implant dentistry unique is the ability to achieve this goal regardless of the atrophy, disease or injury. Implants with small diameters can be used successfully in a variety of clinical situations. A main drawback of Narrow-diameter implants is the possibility of not reaching the required primary stability $(>35 \mathrm{Ncm})$. In such cases, being a one-piece implant, occlusal stresses are expected to disturb proper osseointegration. Lately, 2-piece narrow diameter implants were introduced to the market combining the undisturbed healing period required for proper osseointegration and the avoidance of extensive surgeries for bone augmentation.

OBJECTIVES The purpose of this study is to determine, using 3-dimensional finite element analysis, whether 1-piece and 2-piece narrow diameter implants with equivalent geometries exhibit stresses and strains differently under applied loading conditions when used to retain a mandibular overdenture and, to evaluate how stresses are transmitted to the surrounding bone.

MATERIALS AND METHODS: A computer based numerical model is structured for the anterior segment of the mandible with, 2 narrow diameter implants retaining a mandibular overdenture, one being a 1-piece and the other being a 2-piece. A $35 \mathrm{~N}$, and a $100 \mathrm{~N}$ loads were applied through the overdenture, and Von Mises stresses were analyzed along the implants and the surrounding bone.

RESULTS Stresses around the 2-piece design were greater than those around the 1-piece design, but the values recorded were still below the yield strength of implants and bone.

CONCLUSIONS: A 2-piece narrow diameter implant can be a reliable treatment option to retain overdentures in cases where immediate loading is not recommended.

KEYWORDS: narrow-diameter, 1-piece, 2-piece, overdentures, finite element analysis.

1-BDS, Faculty of Dentistry, Alexandria University, Alexandria, Egypt.

2-Professor of Prosthodontics, Faculty of Dentistry, Alexandria University, Alexandria, Egypt.

3-Lecturer, The Dept. of Naval Architecture and Marine Eng., Faculty of Engineering, Alexandria University, Alexandria, Egypt.
\end{abstract}

\section{INTRODUCTION}

It has always been a challenge to come up with the best way to replace missing teeth since ancient times. Previously, dentures were the standard way of replacing missing teeth. Edentulous patients often do not get used to wearing conventional dentures. Their support is compromised by progressive bone resorption (1).

The use of dental implants to provide support for prostheses offers many advantages compared to the use of removable soft tissues-borne restorations. An endosteal implant can maintain bone width and height as long as the implant remains healthy (2).

The high success rate of interforaminal implants used to support mandibular overdentures is well documented with longitudinal studies up to 12 years (3).

One piece dental implants consist of implant and abutment sections manufactured together as a single unit. They were first introduced in the 1940s, and subsequently manufactured in a variety of designs and materials over 4 decades of clinical use (4).

Two-Piece implants rapidly eclipsed the use of one piece designs and continued to gain acceptance by mainstream dentistry throughout the 1990s. They provide the implant with a period of undisturbed healing before loading (5).

Although contemporary 1- and 2-piece implant systems may have similar gross external geometries, internal variations may result in very different patterns of load distribution. For example, it is currently unknown whether the interfacial break between the implant and abutment of 2-piece systems may enhance or reduce stress concentrations in the crestal bone region compared to 1piece implant systems, which has a solid transition between the components (5).

Sufficient amount of bone for implant placement is an essential prerequisite for long term success implant therapy. This provides a functional and cosmetic implant retained restoration. Lack of bone volume always results in exposure of implant surface, decreased bone-implant interface and ultimately, implant failure. Unfortunately, the resorption of the alveolar ridges may render the placement of standard-diameter implants difficult or impossible. This can be managed either by surgical correction or by positioning the implant in the area with the greatest available bone or simply the use of narrow diameter implants (6).

Consequently, the question has been raised whether optimal implant diameters might be smaller than the "standard diameter" for many indications.

Nowadays, available implants vary in diameter between $1.8 \mathrm{~mm}$ and $7 \mathrm{~mm}$ : implants with diameter less than or equal to $3 \mathrm{~mm}$ are called mini diameter implants (MDI) (7), and are recently named Narrow-diameter or Narrow-body implants.

A main drawback of Narrow-diameter implants is the possibility of not reaching the required primary stability (> 
$30 \mathrm{Ncm}$ ) (8). In such case, being a one-piece implant, occlusal stresses are expected to disturb proper osseointegration.

Lately, 2-piece narrow diameter implants were introduced to the market combining the undisturbed healing period required for proper osseointegration and the avoidance of extensive surgeries for bone augmentation.

There is insufficient evidence on the success rates for all NDIs. Clinical parameters and treatment protocols are often not sufficiently described and no controlled comparative studies are available, resulting in a high risk of bias (9).

In vitro and finite element analyses studies have illustrated that stress values affecting the crestal cortical bone are reciprocal to the dental implant diameter, which means that, especially small diameters result in disadvantageous stress peaks at the implant-bone interface (10).

The idea is to keep stresses below the failure stress of the bone (11).

Investigating the stress distribution can still provide important information for implant design and optimizing implant placement for various types of bone quality (12).

Finite element analysis allows investigators to predict stress distribution in the contact area of the implants with bone using a numerical model of the structures. It is a useful tool to investigate the effect of the biomechanical properties of prostheses on dental implants (13).

\section{MATERIALS AND METHODS}

A computer-based 3D finite element model of the anterior segment of the mandible with an implant retained overdenture was developed using ABAQUS version 14 software to analyze and compare the stresses transmitted to the peri-implant bone and the implants.

The basic mandibular model consisted of a curved beam of $15 \mathrm{~mm}$ radius, $69 \mathrm{~mm}$ length, $14 \mathrm{~mm}$ height, and $6 \mathrm{~mm}$ width. This beam was covered with a 1 mm-thick layer on the buccal, occlusal, and lingual surfaces and a $3 \mathrm{~mm}$ layer at the base to simulate cortical bone: The final external dimensions of the model were as follows, $71 \mathrm{~mm}$ in length, $18 \mathrm{~mm}$ in height, $8 \mathrm{~mm}$ in width (14) (Figure 1).

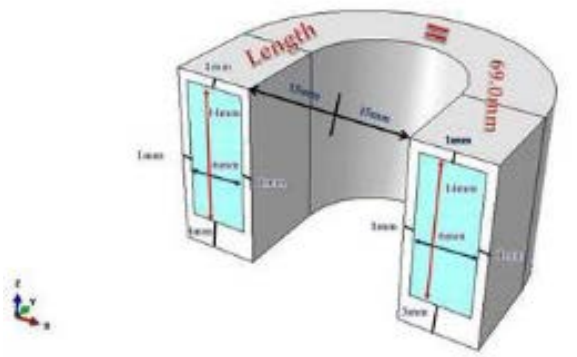

Figure 1: Dimensions of the model of the mandible.

It was deemed unnecessary to construct a model of the

whole mandible. This significantly reduces the modeling and processing time (15).

A 1-piece (Mini1 Sky, Bredent medical, Germany) and a 2-piece (Mini2 Sky, Bredent medical, Germany) narrow diameter implants $(2.8 \times 10 \mathrm{~mm})$ were modeled and placed in the model bilaterally $22 \mathrm{~mm}$ apart(each was $11 \mathrm{~mm}$ from the midline) (16).
The FEM assumed a state of optimal osseointegration, which means that the cortical and cancellous bones are assumed to be $100 \%$ osseointegrated with the implant surface for refinement of the mesh. The ends were constrained and loads of $35 \mathrm{~N}$ and $100 \mathrm{~N}$ were applied simultaneously on both sides over the implants through the overdenture vertically, horizontally and $45^{\circ}$ obliquely.

All materials were presumed linear elastic, homogenous and isotropic (17).

The cortical and cancellous bones were modeled as having elastic properties of a D2-type bone (18).

The corresponding elastic properties such as Young's modulus and Poisson ratio were determined from the literature, as shown in (Table 1) $(15,19-23)$.

Table 1: Elastic properties of each component of the FEM.

\begin{tabular}{||l|c|c||}
\hline \multicolumn{1}{|c|}{ Element } & $\begin{array}{c}\text { Young's modulus } \\
(\mathbf{M P a})\end{array}$ & $\begin{array}{c}\text { Poisson's } \\
\text { ratio }\end{array}$ \\
\hline Cortical bone (19) & 13700 & 0.3 \\
Cancellous bone (19) & 1370 & 0.3 \\
Mucosa (20) & 1 & 0.37 \\
Heat-cure PMMA (21) & 3000 & 0.35 \\
Grade4 titanium(15) & 110000 & 0.35 \\
Stainless steel (22) & 19000 & 0.31 \\
Nylon rubber (23) & 5 & 0.45 \\
\hline
\end{tabular}

All the parameters required to load the model and produce stress patterns were fed to the FE software. On application of forces simultaneously on both sides, Von Mises stress patterns were obtained as contour lines.

Results obtained in this study suggest that stresses within the 2-piece narrow-diameter implant are greater than those within the 1-piece design in all directions of load application.

Stresses in the implant were highest at its neck and in the area of the screw and near the first flutes.

Stresses in the alveolar cortical bone and trabecular bone were highest at the crestal region around both implants, but they occupied larger areas around the 2-piece design, and they were also high near the apex of the implant.

All the obtained values were lower than the yield strength of bone (Cortical (133 MPa), Cancellous (2 MPa)) (24), and implant (483 MPa) (25).

And, the stresses within the bone were even below the critical threshold of bone resorption (60 MPa) (6) (Table 2).

Table 2: Maximum values of stress upon 35N and 100N loading.

\begin{tabular}{|c|c|c|c|c|c|c|}
\hline \multirow{2}{*}{$\begin{array}{l}\text { load Direction \& } \\
\text { Component }\end{array}$} & \multicolumn{2}{|c|}{ Vertical } & \multicolumn{2}{c|}{ Horizontal } & \multicolumn{2}{|c|}{ Oblique } \\
\cline { 2 - 7 } & $\mathbf{3 5}$ & $\mathbf{1 0 0}$ & $\mathbf{3 5}$ & $\mathbf{1 0 0}$ & $\mathbf{3 5}$ & $\mathbf{1 0 0}$ \\
\hline Cortical bone & 2.25 & 3.05 & 5.84 & 16.5 & 2.82 & 2.51 \\
\hline Cancellous & 0.58 & 1.9 & 0.34 & 0.92 & 0.44 & 0.46 \\
\hline 1-Piece & 71 & 189.6 & 6.34 & 11.2 & 3.39 & 10.26 \\
\hline 2-Piece & 174.5 & 419 & 8.05 & 65 & $\begin{array}{c}20.4 \\
9\end{array}$ & 36.46 \\
\hline
\end{tabular}


The highest value of maximum stress was recorded within the 2-piece implant (419 MPa), at the center of the ball abutment upon vertical loading with $100 \mathrm{~N}$ (Figures 2-6).

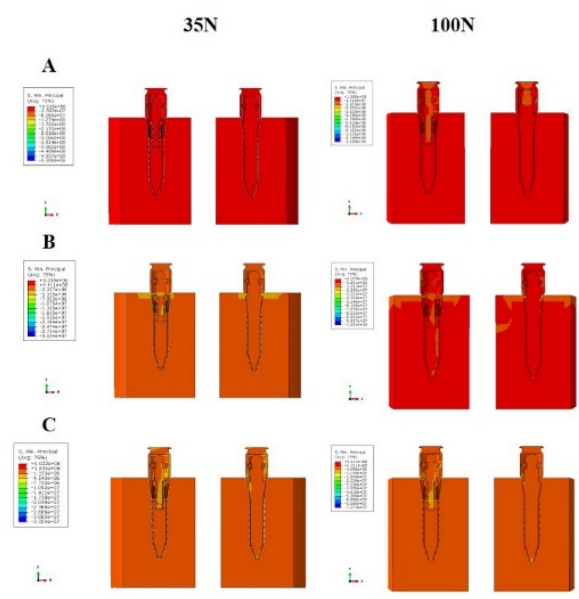

Figure 2: Von Mises stress patterns under $35 \mathrm{~N}$ and $100 \mathrm{~N}$ (A) Vertical loading, (B) Horizontal loading, (C) Oblique loading.

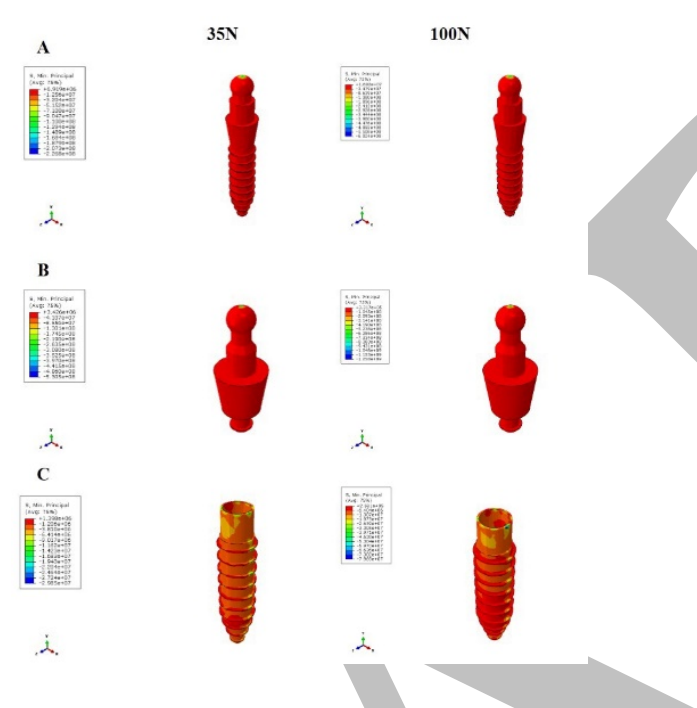

Figure 3: Von Mises stress patterns under $35 \mathrm{~N}$ and $100 \mathrm{~N}$ vertical load (A) 1-piece implant, (B) Abutment of 2-piece implant, (C) Fixture of 2-piece implant.

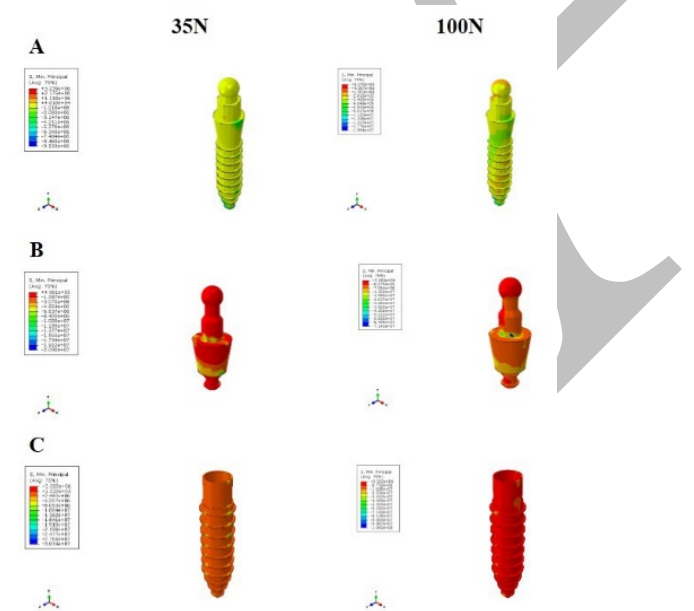

Figure 4: Von Mises stress patterns under $35 \mathrm{~N}$ and $100 \mathrm{~N}$ Horizontal load (A) 1-piece implant, (B) Abutment of 2-piece implant, (C) Fixture of 2-piece implant.

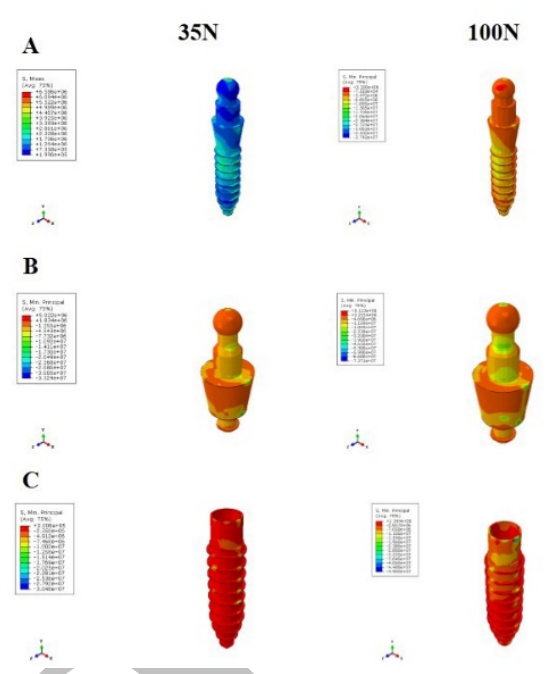

Figure 5: Von Mises stress patterns under $35 \mathrm{~N}$ and $100 \mathrm{~N}$ Oblique load (A) 1-piece implant, (B) Abutment of 2-piece implant, (C) Fixture of 2-piece implant.

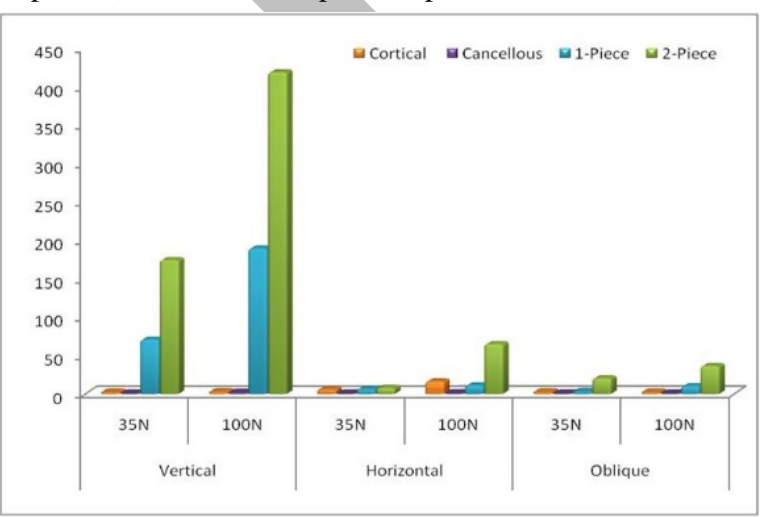

Figure 6: Maximum values of stress upon $35 \mathrm{~N}$ and $100 \mathrm{~N}$ loading.

\section{DISCUSSION}

The evolution of 2-piece designs of narrow diameter implants has given a new choice, as narrow diameter implants don't have to be immediately loaded anymore.

Instead, one can now benefit from the advantages of using the narrow diameter implants along with a period of undisturbed healing with no micromotion or risk of loss of osseointegration in cases where immediate loading is not recommended. However, few researchers have investigated the biomechanical differences quantitavely. So, this study is aimed at investigating the biomechanics of both designs.

Finite element simulations allow the peak values and the distribution of the internal bone stresses and/or strains to be determined easily (26). On top of that, it is capable of providing detailed quantitative data at any location within the mathematical model (27).

The distribution of loads applied to implant-supported prostheses depends on the number, arrangement, placement, design and, stiffness of the implants used, the percentage of bone implant contact, as well as on the shape and stiffness of the prosthesis and type of bone $(6,19)$.

Variable loads that have been applied in this study were chosen as they represent values of the average biting force which can start from $21.3 \mathrm{~N}$ when chewing soft food up to $100 \mathrm{~N}$ which is equal to $10 \mathrm{Kg}$ that is considered to be the closest to the maximum functional biting force in real life situations of denture wearers (28). 
Static load application protocol was used in this study based on the assumption that normally functioning patients do not their teeth in functional contact (chewing) except for approximately 26 minutes all over the day (29).

According to Holmgrem et al (30), complex forces are present in the mouth. So, the study of stress on implants must include not only vertical and horizontal forces, but also combined or oblique forces, since these represent realistic bite directions and may produce greater forces that cause greater damage to the cortical bone. Consequently, forces in this study were applied vertically, obliquely, and horizontally.

The results of this study are consistent with Cehreli et al (31) and Wu AY-J et al (32) findings, as; two-piece implants experience higher mechanical stresses under lateral loading. This is true since, a one-piece implant has a greater mechanical strength in clinical applications than a two-piece implant due to the inherent characteristics of a one-piece structure.

Allum et al, (33) reported that the diameter seems to be the main factor influencing the fatigue strength of small diameter implants. Irrespective of whether one-piece or two-piece implants are used in clinics, caution is necessary for implants with diameters smaller than $3 \mathrm{~mm}$ due to the increased risk of implant fracture.

Stresses in the implant were highest at its neck and in the area of the screw and near the first flutes. This is also supported by Wu AY-J. et al (32).

Stresses in the alveolar cortical bone and trabecular bone are highest at the crestal region around both implants, but they occupy larger areas around the 2-piece design, and they are also high near the apex of the implant.

Some studies related this to the absence of an abutment-fixture connection and retention screw which are features of a two-piece implant. Additionally, the onepiece implants are purported to exhibit minimal resorption of peri-implant bone due to the absence of the microgap, which is a result of the implant-abutment junction. These microgaps have been associated with microleakage and bacterial contamination.

In addition, two-piece small-diameter implants have demonstrated higher mechanical failure rates associated with small diameter screws, screw loosening, and fracture (34).

The results of the present study did not indicate that high stress will always result in overloading-induced bone loss when two-piece implants are used.

It was reported in numerous studies that applying vertical loads on the overdenture generates more stresses than oblique forces do (29).

On the other hand, Luo et al, (35) found that oblique loads increase the resulting stresses by 2.5 times more than vertical loads, this assumption could be confirmed by the laws of solid mechanics which state that when a force in applied to an inclined plane it splits into two, one parallel to the inclined plane and one perpendicular to it (36).

This was found to be in accordance with this study, where it was found that within the surrounding bone, the highest stresses were recorded under horizontal loadings, followed by oblique loadings, and finally vertical loading.

Regarding the implants, the highest stresses were recorded under vertical loading through which nearly all loads were dissipated.
Further investigation of detailed information related to the transmission of bone stress and/or strain around different designs of small-diameter implant is still required in the future.

One of the limitations of this study was the simplified bone shape employed. Although the strength of the bone block used was similar to that of the jaw bone, the strain patterns are likely to vary with the bone geometry. Additionally, bone is a porous material with complex material characteristics (e.g., inhomogeneous, anisotropic, and viscoelastic properties) (2).

Future FE studies could employ more sophisticated simulations of the shape and material properties of bone, which might reduce the inconsistencies between the simulated and experimentally measured surface strains. Furthermore, the present study only applied a static occlusal force in both the experiments and FE simulations. Even though lateral force has been suggested to represent a realistic occlusal direction, chewing simulation-especially for tooth-to-tooth contact-needs to be considered in future investigations.

Other discrepancies in this study included the assumed $100 \%$ bonding between the implant and abutment in the 2-piece implant, and the assumed 100\% BIC. In reality manufacturing tolerances would not allow a $100 \%$ bond between all interlocking implantand-abutment geometrical surfaces, but the friction-fit interface that is achievable would probably render the difference between the simulated model and the actual components negligible in terms of stress generation.

In a similar manner, performing the experiment with $<100 \%$ BIC might affect recorded stress levels somewhat, but the relationships between the variables would probably not be significantly different.

These preliminary findings on the difference in load distribution between 1-piece and 2-piece narrow diameter implants require further investigation.

\section{CONCLUSION}

Within the limitations of this study, the following can be concluded:

- All the stresses recorded were below the yield strength of both implant and bone.

- Stresses recorded around the 2-piece design were higher than those recorded around 1-piece design.

- Stresses were concentrated at the implant-abutment junction and the cervical region of the bone-implant interface.

- Finite element analysis is an effective computational tool that has been adapted from the engineering arena to dental implant biomechanics.

\section{CONFLICT OF INTEREST}

The authors declare that they have no conflicts of interest.

\section{REFERENCES}

1. Martínez-Lage-Azorín JF, Segura-Andrés G, FausLópez J, Agustín-Panadero R. Rehabilitation with implant-supported overdentures in total edentulous patients: a review. J Clin Exp Dent. 2013; 5: 267-72.

2. Misch CE. Contemporary Implant Dentistry. 3rd ed. Missouri: Elsevier Mosby; 2008. 
3. van Steenberghe D, Quirynen M, Naert I, Maffei G, Jacobs R. Marginal bone loss around implants retaining hinging mandibular overdentures, at 4-, 8and 12-years follow-up. J Clin Periodontol. 2001; 28: 628-33.

4. Ring ME. Pause for a moment in dental history. A thousand years of dental implants. A definitive history-part 2. Compend Contin Educ Dent. 1988; 14: 1132-42.

5. Ormianer Z, Ben Amar A, Duda M, Marku-Cohen S, Lewinstein I. Stress and strain patterns of 1-piece and 2-piece implant systems in bone: A 3 dimensional finite element analysis. Implant Dent. 2012; 21: 3945.

6. Arun Kumar G, Mahesh B, George D. Threedimensional finite element analysis of stress distribution around implant with straight and angled abutments in different bone qualities. J Indian Prosthodont Soc. 2013; 13: 466-72.

7. Yaltirik M, Gökçen-Röhlig B, Ozer S, Evlioglu G. Clinical evaluation of small diameter straumann implants in partially edentulous patients: a 5-year retrospective study. J Dent (Tehran). 2011; 8: 75-80.

8. Alsaadi G, Quirynen M, Michiels K, Jacobs R, Van Steengerghe D. A biomechanical assessment of the relation between the oral implant stability at insertion and subjective bone quality assessment. J Clin Periodontol. 2007; 34: 359-66.

9. Bornstein MM, Al-Nawas B, Kuchler U, Tahmaseb A. Consensus statements and recommended clinical procedures regarding contemporary surgical and radiographic techniques in implant dentistry. Int J Oral Maxillofac Implants. 2014; 29(Suppl): 78-82.

10. Baggi L, Cappelloni I, Di Girolamo M, Maceri F, Vairo G. The influence of implant diameter and length on stress distribution of osseointegrated implants related to crestal bone geometry: A three-dimensional finite element analysis. J Prosthet Dent. 2008; 100: 422-31.

11. Frost HM. Wolff's Law and bone's structural adaptation to mechanical use: an overview for clinicians. Angle Orthod. 1994; 64: 175-88.

12. Huang HM, Pan LC, Lee SY, Ho KN, Fan KH, Chen CT. Natural frequency analysis for the stability of a dental implant by finite element method. J Med Biol Eng. 2001; 21: 61-70.

13. Geng JP, Tan KB, Liu GR. Application of finite element analysis in implant dentistry: a review of the literature. J Prosthet Dent. 2001; 85: 58598.

14. Padhye OV, Herekar M, Patil V, Mulani S, Sethi M, Fernandes A. Stress distribution in bone and implants in mandibular 6-implantsupported cantilevered fixed prosthesis: A 3D finite element study. Implant Dent. 2015; 24: 680-5.

15. Rubo JH, Souza EA. Finite element analysis of stress in bone adjacent to dental implants. J Oral Implantol. 2008; 34: 248-55.

16. Aleisa K. The effect of attachment pick-up timing on the retention of locator overdenture posts. Pakistan Oral Dental J. 2012; 32: 543-8.
17. Bellini CM, Romeo D, Galbusera F, Agliardi E, Pietrabissa R, Zampelis A, et al. A finite element analysis of tilted versus non-tilted implant configuration in the edentulous maxilla. Int J Prosthodont. 2009; 22: 155-7.

18. Misch CE. Density of bone: Effect on treatment plans, surgical approach, healing and progressive loading. Int J Oral Implantol. 1990; 6: 23-31.

19. Greco GD, Jansen WC, Landre J, Seraidarian PI. Stress analysis of the free-end distal extension of an implant-supported mandibular complete denture. Braz Oral Res. 2009; 23: 17581.

20. Menicucci G. Mandibular implant-retained overdenture: finite element analysis of two anchorage systems. Int J Oral Maxillofac Implants. 1998; 13: 369-76.

21. Fujimoto T, Niimi A, Murakami I, Ueda M. Use of new magnetic attachments for implantsupported overdentures. J Oral Implantol. 1998; 24: 147-51.

22. Barao VA, Assuncao WG, Tabata LF, Delben JA, Gomes EA, De Sousa EA, et al, Finite element analysis to compare complete denture and implant-retained overdentures with different attachment systems. J Craniofac Surg. 2009; 20: 1066-71.

23. Chun HJ, Park DN, Han CH, Heo SJ, Heo MS, Koak JY. Stress distribution in maxillary bone surrounding overdenture implants with different overdenture attachments. J Oral Rehabil. 2005; 32: 193-205.

24. Ammar HH, Ngan P, Crout RJ, Mucino VH, Mukdadi OM. Three-dimensional modeling and finite element analysis in treatment planning for orthodontic tooth movement. Am J Orthod Dentofacial Orthop. 2011; 139: 59-71.

25. Elias CN, Lima JHC, Valiev R, Meyers MA. Biomedical applications of titanium and its alloys. JOM. 2008; 60: 46-9.

26. Qian J, Wennerberg A, Albrektsson T. Reasons for marginal bone loss around oral implants. Clin Implant Dent Relat Res. 2012; 14: 792807.

27. Ming-Lun H, Chih-Ling C. Application of finite element analysis in dentistry, In: Moratal D (ed). Finite Element Analysis. Croatia: InTech; 2010.

28. Hardtmann G, Proeschel P, Ott RW. Masticatory forces and maximum jaw closure forces of complete denture wearers before and after bite opening. Dtsch Zahnarztl Z. 1989; 44: 26-9.

29. Zarb G, Hobkirk J, Eckert S, Jacob R. Prosthodontic treatment for edentulous patients: Complete dentures and implantsupported prostheses. 13th ed. Part 1: the patient. St. Louis, USA: Elsevier Mosby; 2012.

30. Watanabe F, Hata Y, Komatsu S, Ramos TC, Fukuda H. Finite element analysis of the 
influence of implant inclination, loading position, and load direction on stress distribution. Odontology. 2003; 91: 31-6.

31. Iplikçioğlu H, Akça K, Cehreli MC, Sahin S. Force transmission of one- and two-piece morse-taper oral implants: a nonlinear finite element analysis. Clin Oral Implants Res. 2004; 15: 481-9.

32. Wu AY, Hsu JT, Chee W, Lin YT, Fuh LJ, Huang HL. Biomechanical evaluation of onepiece and two-piece small-diameter dental implants: In-vitro experimental and threedimensional finite element analysis. J Formos Med Assoc. 2006; 115: 794-800.

33. Allum SR, Tomlinson RA, Joshi R. The impact of loads on standard diameter, small diameter and mini implants: A comparative laboratory study. Clin Oral Implants Res. 2008; 19: 553-9.

34. Jackson BJ. Small diameter implants: Specific indications and considerations for the posterior mandible: a case report. J Oral Implantol. 2011; 37: 156-64.

35. Luo X, Ouyang G, Ma X, Jia A, Guo T. The three-dimensional analysis of mandibular overdenture supported by implants. Sheng Wu Yi Xue Gong Cheng Xue Za Zhi. 1998; 15: 167-71.

36. Mechanics of solids I BTME1205. Available at:https://www.slideshare.net/abinashchoudhur $\mathrm{y} /$ module-1-mechanics. 